\title{
Higher incidence of viable Mycobacterium leprae within the nerve as compared to skin among multibacillary leprosy patients released from multidrug therapy
}

\author{
V. P. SHETTY, K. SUCHITRA, \\ M. W. UPLEKAR \& N. H. ANTIA \\ The Foundation for Medical Research, 84-A, R. G. Thadani Marg, \\ Worli, Bombay 400 018, India
}

Accepted for publication 2 December 1996

\begin{abstract}
Summary As identified by a significant growth in the footpads of immunosuppressed mice, the incidence of viable bacteria in a group of 26 multibacillary (BL-LL) patients released from multidrug (MDT) treatment was found to be two times more in the nerves (46\%) as compared to skin (23\%). Evidently there was a positive correlation between the overall bacterial load and the incidence of viable organisms. Bacterial growth was also observed in two out of five cases where neither the skin nor the nerve homogenate had shown any presence of acid-fast bacilli. Histopathology of biopsies, skin as well as nerve, including those having viable bacteria did not show any features of active disease.
\end{abstract}

\section{Introduction}

It has been well documented that peripheral nerves harbour Mycobacterium leprae and its antigens in higher frequency both before and after treatment of leprosy. ${ }^{1-6}$ Investigations to estimate the extent of the viable bacterial load in the peripheral nerve compared with skin, persisting after complete multidrug therapy, have not been carried out so far. The present study investigates the frequency and magnitude of the viable bacterial load in the skin and nerve biopsies obtained from multibacillary leprosy cases (BL-LL) released from multidrug therapy (MDT). The bacterial index (BI) and load/g wt of tissue assessed in the smear and tissue homogenates respectively were compared with their viability status obtained using the footpads of immunosuppressed mice. The histopathology of skin and nerve biopsies was studied with a view to identifying reliable and practical indicator/s if any, of disease activity, treatment success, and differences between skin and nerve tissues. The observations are presented and discussed.

\section{Material and method}

Twenty-six multibacillary cases (BL-LL) of leprosy, between 15 and 55 years of age were 
Table 1. Bacterial Index (BI), load/g wt and viability test results of skin and nerve of post MDT-MB cases

\begin{tabular}{|c|c|c|c|c|c|}
\hline \multirow[b]{2}{*}{ Sl. No. } & \multirow[b]{2}{*}{$\begin{array}{c}\text { Smear } \\
\text { Ave } \mathrm{BI}(+)\end{array}$} & \multicolumn{2}{|c|}{ SKIN } & \multicolumn{2}{|c|}{ NERVE } \\
\hline & & $\begin{array}{c}\text { Bact.load/g wt } \\
(\times 106)\end{array}$ & $\begin{array}{c}\text { No. of +ve takes } \\
\text { Harvests }\end{array}$ & $\begin{array}{l}\text { Bact. load/g wt } \\
(\times 106)\end{array}$ & $\begin{array}{c}\text { No. of +ve takes } \\
\text { Harvests }\end{array}$ \\
\hline 1. & $3 \cdot 3$ & 230 & $0 / 8$ & 330 & $0 / 4$ \\
\hline 2. & $2 \cdot 6$ & 62 & $1 / 3$ & $2 \cdot 2$ & $4 / 4$ \\
\hline 3. & $2 \cdot 2$ & 36 & $3 / 11$ & 16 & $3 / 6$ \\
\hline 4. & $0 \cdot 16$ & 50 & $0 / 5$ & 13 & $0 / 5$ \\
\hline 5. & 1 & 30 & $0 / 11$ & 110 & $3 / 7$ \\
\hline 6. & $4 \cdot 25$ & 250 & $0 / 3$ & 35 & $1 / 4$ \\
\hline 7. & $2 \cdot 1$ & 340 & $2 / 5$ & 13 & $2 / 4$ \\
\hline 8. & 1 & 40 & $0 / 5$ & 40 & $1 / 6$ \\
\hline 9. & 0 & 22 & $0 / 5$ & 0 & $2 / 5$ \\
\hline 10. & 0 & 29 & $4 / 6$ & & $6 / 7$ \\
\hline 11. & 0 & $3 \cdot 4$ & $2 / 3$ & 10 & $2 / 3$ \\
\hline 12. & 0 & 0 & $6 / 12$ & 0 & $4 / 12$ \\
\hline 13. & 0 & 0 & $0 / 7$ & 6 & $0 / 7$ \\
\hline 14. & 0 & $8 \cdot 6$ & $0 / 8$ & 14 & $0 / 8$ \\
\hline 15. & 0 & $3 \cdot 2$ & $0 / 10$ & $9 \cdot 9$ & $0 / 10$ \\
\hline 16. & 0 & 0 & $0 / 6$ & $0 \cdot 6$ & $0 / 5$ \\
\hline 17. & 0 & 0 & $0 / 8$ & $1 \cdot 7$ & $1 / 8$ \\
\hline 18. & 0 & $3 \cdot 9$ & $0 / 5$ & $6 \cdot 5$ & $0 / 8$ \\
\hline 19. & 0 & $0 \cdot 95$ & $0 / 3$ & $0 \cdot 96$ & $0 / 5$ \\
\hline 20. & 0 & 0 & $0 / 5$ & $1 \cdot 6$ & $0 / 4$ \\
\hline 21. & 0 & 0 & $0 / 7$ & 0 & $0 / 10$ \\
\hline 22. & 0 & 1 & $0 / 7$ & $2 \cdot 1$ & $0 / 8$ \\
\hline 23. & 0 & $0 \cdot 37$ & $0 / 6$ & $90 \cdot 7$ & $0 / 8$ \\
\hline 24. & 0 & 0 & $0 / 7$ & 0 & $1 / 3$ \\
\hline 25. & 0 & 0 & $0 / 5$ & 0 & $0 / 4$ \\
\hline 26. & 0 & 0 & $0 / 6$ & 0 & $0 / 8$ \\
\hline
\end{tabular}

+ve takes means $M$. leprae fold increase $\geq 10$ fold

included in the study. All the patients had completed a minimum of 24 months of WHOrecommended MDT for multibacillary leprosy, namely $600 \mathrm{mg}$ RFP and clofazimine (CLF) $300 \mathrm{mg}$ once a month (supervised) $50 \mathrm{mg}$ CLF and dapsone (DDS) $100 \mathrm{mg}$ daily. One of the patients (No. 4) was on DDS monotherapy before starting on MDT and five others (Nos 1, 2, 19, 20 and 26, Table 1) had received, 32 to 42 months of MDT. The remaining 21 patients had received 24 months of MDT-MB. One of the patients (No. 7) had repeated episodes of ENL reaction and was given prednisolone during the reaction. Biopsies were obtained between 2 months and 6 months of release from treatment (RFT) to ensure that there was no circulating active drug components and to avoid any confusion with relapse or reinfection. All the patients were regular in their intake of prescribed treatment. Slit-skin smears from 6 sites were taken from all the patients and bacterial indices (BI) were recorded along with a detailed clinical examination and charting.

\section{BIOPSY}

Using local anaesthesia a deep incision skin biopsy from a site that showed highest BI or an earlobe biopsy were taken from cases who were smear negative and a biopsy of thickened 
Table 2 Size of the inocula and the footpad harvest results of only the cases showing $>10$ fold growth

\begin{tabular}{|c|c|c|c|}
\hline \multirow[b]{2}{*}{ Case S. No. } & \multirow[b]{2}{*}{ Inocula size $\times 10^{4}$} & \multicolumn{2}{|c|}{${ }^{*}$ Count/footpad $\times 10^{4}$} \\
\hline & & with skin homogenate & with nerve homogenate \\
\hline 2 & $\begin{array}{r}\mathrm{S}=5 \\
\mathrm{~N}=3\end{array}$ & $10,35,122$ & $155,56,122,48$ \\
\hline 3 & $\begin{array}{r}\mathrm{S}=6 \\
\mathrm{~N}=2\end{array}$ & $\begin{array}{l}74,44,21,11 \\
14,63,113,14 \\
14,50,26\end{array}$ & $30,17,29,20,3,6$ \\
\hline 5 & $\begin{array}{r}\mathrm{S}=5 \\
\mathrm{~N}=2\end{array}$ & $\begin{array}{l}26,3,8,3,4,3 \\
2,8,0,3,2\end{array}$ & $\begin{array}{l}31,56,44,45,22, \\
25,0\end{array}$ \\
\hline 6 & $\begin{array}{r}\mathrm{S}=7 \\
\mathrm{~N}=2\end{array}$ & $10,2,5$ & $35,0,0,0,3,2$ \\
\hline 7 & $\begin{array}{l}\mathrm{S}=2 \\
\mathrm{~N}=0 \cdot 2\end{array}$ & $39,26,5,8,3$ & $8,3,2,10$ \\
\hline 8 & $\begin{array}{r}S=4 \\
N=2\end{array}$ & $3,5,8,5,0$ & $97,2,0,0,2,2$ \\
\hline 9 & $\begin{aligned} \mathrm{S} & =2 \\
N & =<1\end{aligned}$ & $5,2,0,4,3$ & $59,0,3,0,0$ \\
\hline 10 & $\begin{array}{r}\mathrm{S}=1 \\
\mathrm{~N}=1\end{array}$ & $\begin{array}{l}0,0,0,11 \\
13,7,6\end{array}$ & $\begin{array}{l}18,108,61,21 \\
8,17,17\end{array}$ \\
\hline 11 & $\begin{aligned} S & =1 \\
N & =1\end{aligned}$ & $2,11,4,6$ & $2,37,3,45$ \\
\hline 12 & $\begin{aligned} \mathrm{S} & =<1 \\
\mathrm{~N} & =<1\end{aligned}$ & $\begin{array}{l}1,20,0,3,2 \\
0,2,5,3,0,0\end{array}$ & $\begin{array}{l}0,0,8,0,2, \\
15,2,1,0,0\end{array}$ \\
\hline 17 & $\begin{array}{r}S=1 \\
N=1\end{array}$ & $\begin{array}{l}0,0,0,3,2 \\
2,1,2,1\end{array}$ & $\begin{array}{l}2,2,79,0,0 \\
3,0,0\end{array}$ \\
\hline 24 & $\begin{aligned} \mathrm{S} & =<1 \\
\mathrm{~N} & =<1\end{aligned}$ & $\begin{array}{l}0,0,0,0,0, \\
0,0\end{array}$ & $0,27,2,0,0$ \\
\hline
\end{tabular}

* Counts rounded to the nearest whole number

$0=$ No. bacilli in $>100$ folds

sural nerve were taken from all the cases after obtaining an informed consent. A part of each skin and nerve biopsies were fixed and processed for light microscopy and another part used for bacterial harvest. Nerve biopsies were stripped clean of all the epineural and perineural connective tissue before the homogenization was carried out using a Corning glass homogenizer. The bacterial load/g weight of tissue was determined using the standard protocol. ${ }^{7}$ All the skin and nerve homogenates (26 each) regardless of their bacterial status were injected into the hind footpads of Swiss White mice, immunosuppressed using T200 $\times 5 \mathrm{R}$ protocol. ${ }^{8}$ Inocula containing not more than $10^{5}$ in $0.03 \mathrm{ml}$ were injected into both the hind footpads of 8-12 mice within $24 \mathrm{~h}$ of collecting the biopsy. Footpad harvests were scheduled for the 12 th month. However if any mice died or were sick after the 6th postinfection month, footpad harvests were carried out to record the counts. The fold increase per footpad were calculated from the number inoculated. Homogenization of the footpads was carried out using a 'OMNI' homogenizer that had a foam-reducing style generator, treatable volume of 3-5 $\mu 1$ and a speed of 0-18,000 rpm (OMNI Cat No. 15005). 


\section{Results}

BACTERIAL INDEX AND LOAD/GWT IN SKIN AND NERVES

Of the $26 \mathrm{MB}$ cases included in this study only 8 were smear positive and all the smear positive cases had a pretreatment BI status of over $5+$. In these smear positive cases the average bacterial index (BI) assessed by the slit-skin smears taken from 6 sites ranged between $0 \cdot 16+$ and $4 \cdot 25+$ (see Table 1 ) and bacterial load/g wt of biopsies, both skin and nerve were between $10^{7}$ to $10^{8}$. In 13 out of the 18 smear negative cases, M. leprae counts were obtained in the homogenates. In one case (1/13) only skin was positive, in three cases $(3 / 13)$ only nerves were positive while in the remaining 9 cases $(9 / 13)$ both skin and nerve homogenates were positive. In all except one nerve homogenate bacterial load/g wt were between $10^{5}$ and $10^{6}$. In one of the nerve homogenates the count was $9 \cdot 7 \times 10^{7} / \mathrm{g}$ wt. In the remaining 5 smear negative cases no detectable counts were obtained in the homogenates of either skin or nerve.

VIABILITY OF M. LEPRAE IN SKIN AND NERVE OF POST MDT-MB CASES.

Out of 26 postMDT-MB cases included in this study, $12(46 \cdot 2 \%)$ showed presence of a significant number of viable bacteria as evidenced by over 10 -fold growth in the footpads of immunosuppressed mice, in skin and/or nerve biopsies (see Tables 1 and 2). In half of them positive takes were obtained with both skin and nerve while in the remaining half, only nerves were positive. On comparing the overall bacterial load with the viability test results (see Table 1), 6 of the 12 cases ( $50 \%$ ) that showed positive takes were smear positive and they had a bacterial load per g wt more than $10^{7}$. There were 4 positive takes $(33 \cdot 3 \%)$ in the lower BI group, i.e. $10^{5}$ to $10^{6} \mathrm{ML} / \mathrm{g} \mathrm{w}$. While one skin biopsy and two nerve biopsies derived from two patients, that showed positive takes in the footpad have had no detectable counts in the homogenates of the skin and nerve.

\section{HISTOPATHOLOGY}

Chronic granulomatous cellular infiltration was seen in all except 3 skin and 6 nerve samples. There was a considerable variation in the extent of cellular infiltrate. Some of the common features noted were: $a$, the higher the bacterial load the higher the cellular infiltrate; and b, foamy cells were normally seen as aggregates around the blood vessels and adnexa in the skin and around blood vessels in nerves (see Figure 1). What appeared to be a fresh influx of perivascularly located mild lymphocytic infiltrate were seen in 3 skin biopsies (Nos 13, 14 and 15) and 6 nerve biopsies (Nos 13, 14, 15, 19, 20 and 23).

\section{Discussion}

One of the main objectives of this study was to record the relative difference in the incidence of the viable bacteria in the contemporary skin and nerve biopsies obtained from multibacillary cases released from multidrug therapy (MB-MDT-RFT). Of the 26 MB-MDTRFT cases studied 6 showed viable bacteria in both skin and nerve, and in another 6 cases viable bacteria were detected in the nerve only. Thus the incidence of viable bacteria in this group of MB-MDT-RFT cases was found to be two times more in the nerve compared with 

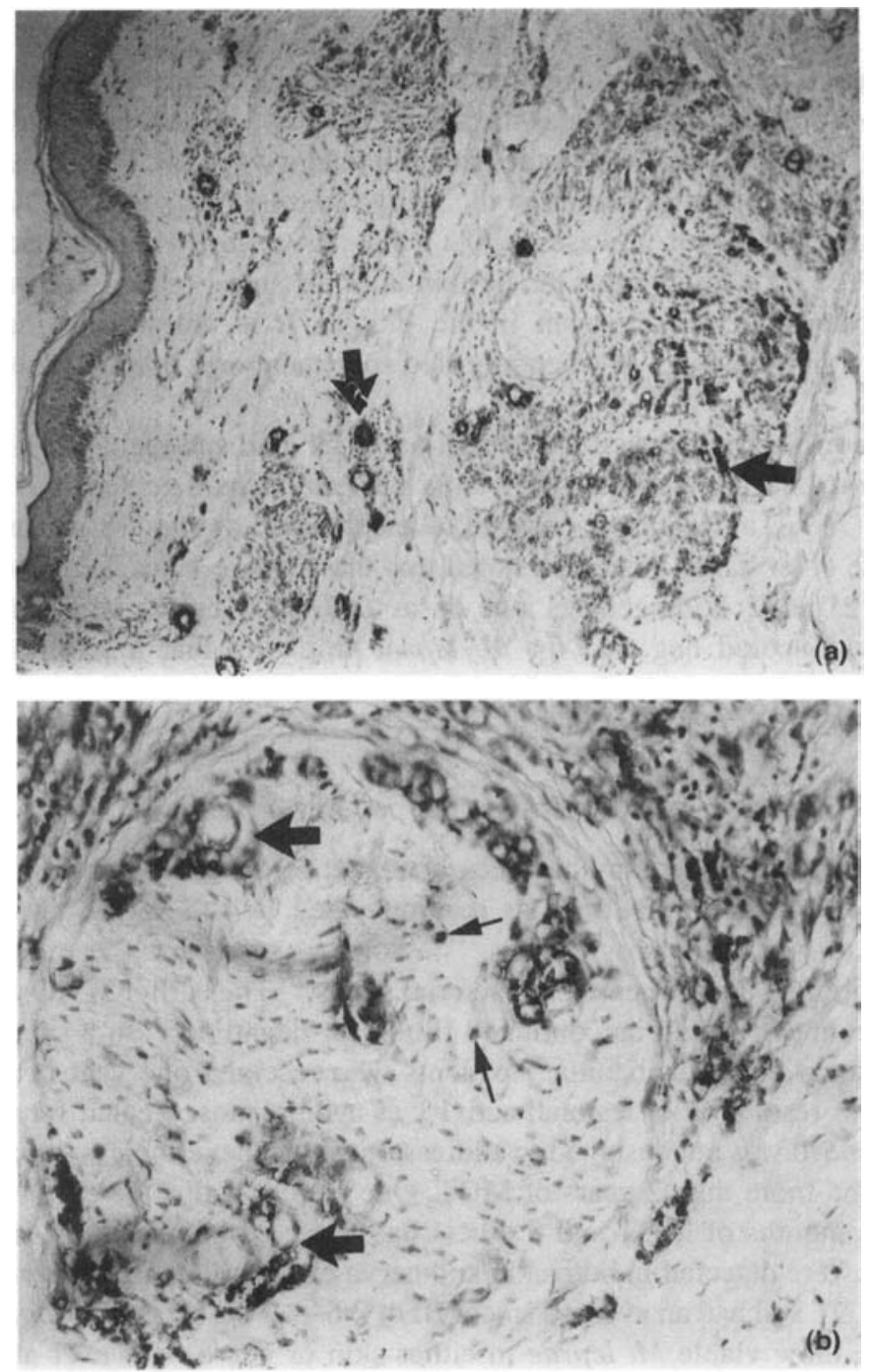

Figure 1(a). Part of the earlobe biopsy from patient S.No.7, where both skin and nerve were positive for viable $M$. leprae. Paraffin embedded section immunostained with $M$. leprae cross reactive anti BCG antibody in an indirect peroxidase assay. Note the presence of large aggregates of BCG positive foamy cells (arrow) along the dermis. Mag. $\times 100$. (b) Part of the sural nerve T.S. from the above patient similarly stained. Note the presence of BCG positive foamy cell aggregates around the endoneurial blood vessels (big arrow) and Schwann cells (small arrow) on a background of dense collagen. Mag. $\times 120$.

skin. This was despite the finding that in several cases, the skin showed a higher bacterial load/g wt compared with nerve (see Table 1). Apart from this difference between skin and nerve it is noteworthy that the present study also records a much higher incidence of viable bacteria in the skin, i.e. $23 \%$ as against $9 \%-10 \%$ documented by the THELEP study reported in the year $1987 .^{9}$ 
BACTERIAL LOAD AND INCIDENCE OF VIABLE BACTERIA

The bacteriological index (BI) as assessed by the multiple smears is the most practical and commonly used tool for monitoring at the field level. ${ }^{10-12}$ It must be noted that the smears scored negative in all the cases where the bacterial load/g wt was $<10^{6}$. Smear positivity was recorded in 8 out of 26 cases included in the study (30.8\%). Not surprisingly the skin biopsy homogenates were positive in 18 cases $(68 \%)$ while nerve biopsy homogenates were positive in 20 cases (76.9\%). This highlights the limitation of the smear techniques as the indicator of presence or absence of an organism in the biopsy. It is noteworthy that the detection sensitivity was improved by $37 \%$ when biopsied specimen were homogenized and scored for AFB.

A positive correlation between the overall bacterial load and incidence of viable bacteria was evident from the findings that the viable bacteria were detected in 6 out of 8 smear positive cases $(75 \%)$, as against 6 positive takes obtained among 18 smear negative cases $(33.3 \%)$. On the other hand, it must be noted that the positive takes were also obtained with one skin and 2 nerve homogenates out of a total of 5 cases, where both smear and homogenates had scored negative for $M$. leprae implying that a subminimal but viable load of bacteria were present in these biopsies.

DURATION OF TREATMENT AND INCIDENCE OF VIABLE M. LEPRAE

The duration of multidrug therapy has been a subject of debate. ${ }^{13}$ For multibacillary cases, two years of fixed duration, 3 drugs as recommended by the WHO has been the policy adopted by several national programmes. ${ }^{14,15}$ Some suggest that the treatment should be extended in relation to the pretreatment bacterial status. ${ }^{16}$ The earlier WHO recommendation was that the treatment should be continued till smear negativity. ${ }^{9}$ In a small clinical-based study it was shown that paucibacillary patients who received one year of MDT-PB fared better in terms of resolution of lesional activity as against those treated for 6 months. ${ }^{17}$ The present study indeed was not designed to address this issue, nevertheless there were 6 patients who had received more than 2 years of MDT. One patient had received 24 months of DDS followed by 24 months of MDT and 5 others had received more than 32 months of MDT. Viable bacteria were detected in both skin and nerve of one of the patients who had received 32 months of MDT and had an average smear BI of $2 \cdot 6+$ at the time of biopsy. The remaining 5 cases did not show viable $M$. leprae in either skin or nerve. However absence of viable bacteria among these patients could not be attributed to the extended treatment alone, as there was also significant difference in their pretreatment BI. It is of relevance to mention that no viable bacteria were detected in a similar study carried out on contemporary skin and lymph node biopsies obtained from $11 \mathrm{LL}$ cases, who had received 5 years of DDS monotherapy prior to 2 years of MDT. ${ }^{18}$ All the patients included in this study had a comparable posttreatment BI of over $3+$. However as pointed out by the authors, use of non immunosuppressed mice in their study might have restricted the sensitivity of test system. The THELEP study, on the other hand, using immunosuppressed mice records no difference in the degree of persisters in the skin biopsy, with treatment duration ranging from 3 months to 2 years and with different regimens. ${ }^{9}$ These results in turn have led to the acceptance of persisters as unavoidable and of little significance.

A significant drop in prevalence and exceptionally low relapse rate are the two prominent justifications offered in favour of fixed-duration therapy. However events subsequent to 
similar exceptions in the early years of dapsone monotherapy and the emergence of multidrug resistance despite short-course chemotherapy in tuberculosis warrants a cautious approach and careful monitoring of the long-term sustenance of MDT in multibacillary leprosy.

The presence of viable bacteria in 12 of the $26 \mathrm{MB}$ cases $(46 \%)$ that were released from a well-implemented regimen of WHO-MDT in the present study should be viewed with concern, for it indicates a very poor cure rate. This study, the first of its kind, also establishes that the incidence of viable bacteria in the peripheral nerve is twice as high as compared to skin. Since all the nerves included in this study were grossly involved, the prima-facie evidence $^{19}$ suggest that the penetration of the drugs into the endoneurial compartment or to the Schwann cell per se may have little to do with the higher incidence of viability. On the other hand, immunological seclusion of the peripheral nerve or a yet unknown microenvironment of the Schwann cell may be playing a role in promoting the bacterial survival.

Histopathology did not prove very useful except for the findings that all the biopsies that showed viable bacteria did not show evidence of active disease. This was partly due to the time of biopsy. Whether use of immunotherapy will have any beneficial effect in bringing down the 'viable' bacterial load from the peripheral nerve compartment remains to be seen. Results obtained in the present study make a strong case for such monitoring.

\section{Acknowledgments}

We gratefully acknowledge the help of Dr Satish Arolkar with the biopsies. Dr R. Ganpati, Director, BLP for referring some of the patients for this study. Mrs Jayalakshmi for typing the manuscript. This data was presented in part at the 14th International Leprosy Congress held at Orlando, 1993.

\section{References}

${ }^{1}$ Bhatt PV, Antia NH. Study of viability of M. leprae from multiple tissue biopsies of ten leprosy patients using the mouse foot pad technique. Lepr Ind 1976; 46(2): 1-10.

2 Antia NH, Pandya NJ. Qualitative histology and quantitative bacteriology in various tissues of 50 leprosy patients. Lepr Rev. 1976; 47(3): 175-183.

3 Antia NH, Kamala N. Persistence of M. leprae in peripheral nerve. Ind. J. Med. Res. 1983; 77(4): 42-422.

${ }^{4}$ Barros U, Shetty VP, Antia NH. Demonstration of $M$. leprae antigen in nerves of tuberculoid leprosy. Acta. Neuropathol. (Berl). 1987; 73: 387-392.

5 Shetty VP, Suchitra K, Uplekar MW, Antia NH. Persistence of $M$. leprae in the peripheral nerve as compared to skin of multidrug treated leprosy patients. Lepr. Rev. 1992; 63: 329-336.

6 Shetty VP, Uplekar MW, Antia NH. Immuno-histochemical localization of mycobacterial antigens within the peripheral nerves of treated leprosy patients and their significance to nerve damage in leprosy. Acta Neuropathol. 1994; 88: 300-306.

7 WHO. Laboratory techniques for leprosy. 1987; CDS/LEP 86.4

8 Colston MJ. Application of thymectomized irradiated mouse to the detection of persisting M. leprae. Int. J. Lepr. 1987; 55: 859-863.

9 THELEP Subcommittee on clinical trial of chemotherapy of leprosy. Scientific working group UNDP/World Bank WHO Special Programme for research and training in tropical diseases. Persisting M. leprae among THELEP trial patients in Bamako and Chingleput. Lepr. Rev. 1987; 58: 325-327.

${ }^{10}$ Waters MRF, Rees RJW. Changes in the morphology of M. leprae in patients under treatment. Int. J. Lepr. 1962; 30: $266-277$.

11 Ridley DS. Bacterial indices. In: Leprosy in theory and practice. Ed. Cochrane RG, Davey TF. Johnwright \& Sons Ltd. Bristol. 1964; pp. 620-622.

12 McRae DH, Shepard CC. Relationship between staining quality of M. leprae and infectivity for mice. Infect. Immun. 1971; 3: 116-200. 
13 Ganpati R, Pai R, Gandevar KL, Tharessia XJ. For how long should a multibacillary leprosy patient be treated (?). Ind. J. Lepr. 1989; 61: 467-471.

${ }^{14}$ NLEP overview. Count down towards irradication of leprosy from India, Ministry of Health and Family Welfare, New Delhi. (1987).

15 NLEP (1994). Guidelines for multidrug treatment in non endemic districts. Leprosy division, Directorate General of health Services, Govt. of India, New Delhi.

16 Katoch K, Natarajan M, Bagga A, Katoch VM. Clinical and bacteriological progress of highly bacillated BL-LL patients discontinuing treatment after different periods of MDT. Int. J. Lepr. 1991; 59(2): 248-254.

17 Katoch K, Ramanathan U, Natarajan M, Bagga AK, Bhatia AS, Saxena RK, Ramu G. Relapses in paucibacillary patients after treatment with three short-term regimen. Int. J. Lepr. 1989; 57: 458-464.

18 Sivaprasad N, Snehalatha S, Lobo D, Aschhoff M, Job CK. Viability of M. leprae in lepromatous patients after five years of dapsone, monotherapy supplemented with two years of multidrug therapy. 1995; 64: 427. 433.

19 Save MP, Shetty VP, Antia NH. Intracellular localization of dapsone and rifampicin in skin and nerve of multidrug treated leprosy patients. Ind. J. Lepr. 1995; 67(3) 273-284. 